\title{
Serum Myeloperoxidase Level Is Associated with Heart-Type Fatty Acid-Binding Protein but Not Troponin T in Patients with Chronic Heart Failure
}

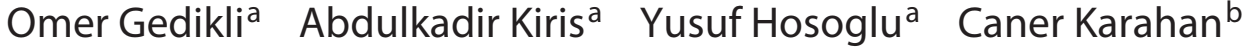 \\ Sahin Kaplan ${ }^{\mathrm{a}}$ \\ ${ }^{\mathrm{a}}$ Department of Cardiology, Faculty of Medicine, Karadeniz Technical University, and ${ }^{\mathrm{b}}$ Department of \\ Biochemistry, Özel Yıldızlıgüven Hospital, Trabzon, Turkey
}

\section{Key Words}

Myeloperoxidase $\cdot$ Myocardial damage $\cdot$ Heart failure

\begin{abstract}
Objective: Our aim was to investigate the possible relationship between myeloperoxidase (MPO) and myocardial damage markers such as heart-type fatty acid-binding protein (H-FABP) and troponin T (TnT) in patients with chronic heart failure (HF). Materials and Methods: Forty-two consecutive patients (age range: $27-80$ years) with chronic HF were enrolled in the study. Serum H-FABP, TnT and MPO levels were measured. Routine biochemical and clinical parameters were recorded. Echocardiographic examinations were performed on all patients. A linear regression analysis was performed to determine the correlates of serum H-FABP. Results: The MPO, H-FABP and TnT levels were $255 \pm 227$, $60.6 \pm 48.5$ and $0.07 \pm 0.15 \mathrm{ng} / \mathrm{ml}$, respectively. In multiple linear regression analysis, age $(\beta=-0.36, p=0.006)$, creatinine level $(\beta=0.3, p=0.024)$ and serum MPO level $(\beta=0.41$, $p=0.009$ ) were significant determinants of H-FABP levels. Bivariate predictors were not significantly associated with TnT levels in linear regression analyses. Conclusions: The MPO was significantly associated with serum H-FABP levels but not with TnT.

(c) 2014 S. Karger AG, Basel
\end{abstract}

\section{Introduction}

Myeloperoxidase (MPO) is a biomarker of inflammation and oxidative stress produced by neutrophils, monocytes and endothelial cells [1]. It plays an important role in the host defense against bacteria and viruses. There is ongoing interest in the use of MPO as a biomarker in different cardiovascular diseases [2]. MPO is associated with mortality, disease progression and severity in heart failure (HF) $[3,4]$. In animal and clinical studies, it has been shown that MPO may be related to cardiac remodeling and left ventricular (LV) function $[5,6]$. There are also increased levels of MPO in patients with coronary artery disease $[7,8]$.

The presence of ongoing myocardial damage is an important predictor of prognosis in patients with $\operatorname{HF}[9,10]$. Heart-type fatty acid-binding protein (H-FABP) and troponin $\mathrm{T}(\mathrm{TnT})$ have been widely used as markers of myocardial damage [9-11]. H-FABP is a low-molecularweight $(15 \mathrm{kD})$ cytoplasmic protein, which has the role of intracellular transportation of free fatty acids in the cardiomyocyte [12]. It has been reported to have the potential to reflect a small extent of ongoing myocardial damage [10]. Cardiac troponins are myofibrillar cardiac proteins that control the interaction of actin and myosin [13].

\begin{tabular}{ll}
\hline KARGER 125:s & $\begin{array}{l}\text { () 2014 S. Karger AG, Basel } \\
1011-7571 / 14 / 0241-0042 \$ 39.50 / 0 \quad \text { Karger }\end{array}$ \\
$\begin{array}{l}\text { E-Mail karger@karger.com } \\
\text { www.karger.com/mpp }\end{array}$ & $\begin{array}{l}\text { This is an Open Access article licensed under the terms of the } \\
\text { Creative Commons Attribution-NonCommercial 3.0 Un- } \\
\text { ported license (CC BY-NC) (www.karger.com/OA-license), } \\
\text { applicable to the online version of the article only. Distribu- } \\
\text { tion permitted for non-commercial purposes only. }\end{array}$
\end{tabular}

Omer Gedikli, MD

Department of Cardiology, Faculty of Medicine

Karadeniz Technical University

TR-61080 Trabzon (Turkey)

E-Mail dromergedikli@gmail.com 
Previous studies have shown that both H-FABP and TnT are associated with cardiac events in patients with chronic HF $[9,10]$. The potential effect of MPO on myocardial damage has not been studied in patients with HF. The aim of this study was to investigate the relationship between MPO and myocardial damage markers such as H-FABP and TnT.

\section{Subject and Methods}

Subjects

Forty-two consecutive chronic HF patients who were admitted to our outpatient clinic were prospectively studied. Demographic, clinical and routine biochemical data were recorded. Echocardiographic examination was performed on all patients with the Vingmed System 7 (GE Healthcare, Horten, Norway). LV functions were measured according to the American Echocardiography Society guideline [14]. Patients with hemolytic, hepatic or renal diseases (serum creatinine concentration $\geq 1.4 \mathrm{mg} / \mathrm{dl}$ ) and a history of acute coronary syndrome within the last 3 months were excluded from the study. Written informed consent was obtained from each subject, and the Institutional Ethics Committee approved the study protocol.

\section{Measurement of Myeloperoxidase}

Blood samples for measuring MPO levels were drawn from an antecubital vein. Serum was immediately obtained by centrifugation of the blood at $3,000 \mathrm{rpm}$ and $4^{\circ} \mathrm{C}$ for $10 \mathrm{~min}$ and then stored in several aliquots at $-20^{\circ} \mathrm{C}$ until assayed. Serum MPO levels in all samples were measured using commercially available ELISA kits (Immundiagnostik AG, Bensheim, Germany).

\section{Measurement of Myocardial Damage Markers}

Blood samples were drawn from an antecubital vein. The serum was obtained after a centrifugation of $3,000 \mathrm{rpm}$ at $4^{\circ} \mathrm{C}$ for $10 \mathrm{~min}$ and stored at $-70^{\circ} \mathrm{C}$ until analysis. H-FABP levels in all the subjects were measured with commercially available ELISA kits (BioCheck Inc., Foster City, Calif., USA). The normal range for H-FABP levels was $1.6-19 \mathrm{ng} / \mathrm{ml}$ [15]. For this equipment, the minimal detectable concentration for the H-FABP assay is 0.25 $\mathrm{ng} / \mathrm{ml}$ and the interassay and intra-assay variations for determining $\mathrm{H}-\mathrm{FABP}$ are 10 and $8 \%$, respectively [15]. The TnT levels were determined by means of a quantitative electrochemiluminescence assay (Elecsys 2010; Roche, Mannheim, Germany) with a cutoff value $<0.010 \mathrm{ng} / \mathrm{ml} \mathrm{[16]}$.

\section{Statistical Analyses}

Continuous data are expressed as means \pm SD. Data distribution was assessed using the Kolmogorov-Smirnov test. Serum HFABP and TnT levels, with respect to the demographic characteristics and drug use, were compared using the Mann-Whitney U test. The Spearman correlation analysis was performed to estimate the correlation between myocardial damage markers and other variables. Linear regression analysis was performed to identify the independent predictors of serum H-FABP and TnT. For linear regression, factors showing a value of $\mathrm{p}<0.1$ in the univariate analysis were selected. $\mathrm{p}<0.05$ was considered statistically significant.

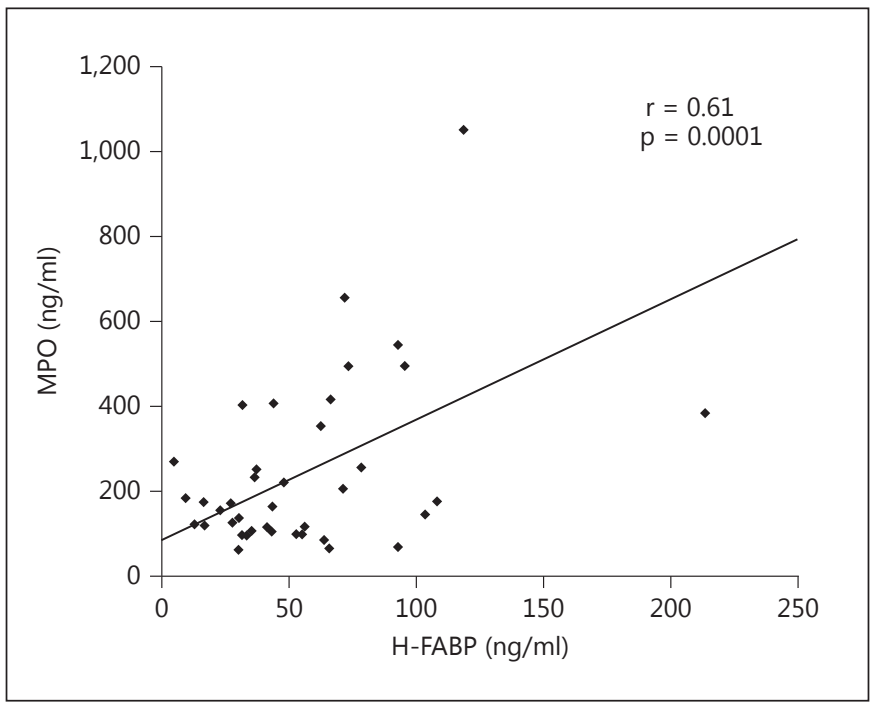

Fig. 1 Correlation of MPO and H-FABP.

Statistical analyses were performed using SPSS software (v10.0, SPSS Inc., Chicago, Ill., USA).

\section{Results}

The 42 patients with chronic HF had a mean age of 67 \pm 12 years. Demographic, clinical and echocardiographic characteristics of the study population are reported in table 1. Routine biochemical parameters and serum levels of MPO, H-FABP and TnT are also given in table 1.

A positive correlation was found between $\mathrm{H}-\mathrm{FABP}$ and blood urea nitrogen (BUN; $r=0.38, p=0.013$ ), creatinine $(r=0.32, p=0.034)$ and $\mathrm{MPO}(\mathrm{r}=0.61, \mathrm{p}=0.0001$; fig. 1). A negative correlation was found between $\mathrm{H}$ FABP and age $(\mathrm{r}=-0.28, \mathrm{p}=0.07)$, sodium $(\mathrm{r}=-0.27$, $\mathrm{p}=0.075)$, hemoglobin $(\mathrm{r}=-0.28)$ and ejection fraction (EF; $r=-0.26, p=0.08$; table 2). No significant relationships were observed between H-FABP and LV diameters and volumes. H-FABP levels were similar in patients who used angiotensin-converting enzyme inhibitors, $\beta$-blockers, digoxin and diuretics and those who did not. $\mathrm{H}$-FABP levels were significantly higher in females than males ( $95.6 \pm 76.5$ vs. $45.8 \pm 24.7, \mathrm{p}=0.03)$. Other demographic characteristics did not significantly affect serum $\mathrm{H}$-FABP levels. Multiple linear regression analyses showed that the significant determinants of $\mathrm{H}-\mathrm{FABP}$ levels were age $(\beta=-0.36, p=0.006)$, serum creatinine level $(\beta=0.3, p=0.024)$ and serum MPO level $(\beta=0.41, p=$ 
Table 1. Baseline characteristics of the study population

\begin{tabular}{lllc}
\hline Variables & Value & Variables & Value \\
\hline Age, years & $67 \pm 12$ & LVEDD, mm & $64.2 \pm 8.3$ \\
Male, \% & 57 & LVESD, mm & $53.5 \pm 9.2$ \\
Smoking, \% & 12 & LVEDV, ml & $152 \pm 57$ \\
Hypertension, \% & 38 & LVESV, ml & $109 \pm 45$ \\
Diabetes, \% & 23 & EF, \% & $27 \pm 10$ \\
BMI & $24.5 \pm 4.2$ & Glucose, mg/dl & $115 \pm 46$ \\
AF, \% & 64 & BUN, mg/dl & $29 \pm 9$ \\
Etiology of HF & & Creatinine, mg/dl & $1 \pm 0.22$ \\
$\quad$ Ischemic, \% & 52 & Hemoglobin, g/dl & $12.8 \pm 2$ \\
$\quad$ Valvular, \% & 13 & WBC $\times 10^{3} / \mu l$ & $8 \pm 1.8$ \\
$\quad$ DCMP, \% & 35 & P count $\times 10^{3} / \mu l$ & $213 \pm 65$ \\
Medications & & Sodium, mEq/l & $136 \pm 4.3$ \\
$\quad$ ACE inhibitors, \% & 66 & Potassium, mEq/l & $4.5 \pm 0.68$ \\
$\quad \beta$-Blocker, \% & 40 & MPO, ng/ml & $255 \pm 227$ \\
$\quad$ Digoxin, \% & 28 & H-FABP, ng/ml & $60.6 \pm 48.5$ \\
$\quad$ Diuretics, \% & 70 & TnT, ng/ml & $0.07 \pm 0.15$ \\
\hline
\end{tabular}

Values represent means $\pm \mathrm{SD}$ unless otherwise stated. $\mathrm{ACE}=$ Angiotensin-converting enzyme; $\mathrm{AF}=$ atrial fibrillation; $\mathrm{BMI}=$ body mass index; DCMP = dilated cardiomyopathy; LVEDD $=\mathrm{LV}$ end-diastolic diameter; LVEDV $=\mathrm{LV}$ end-diastolic volume; LVESD $=$ LV end-systolic diameter; LVESV $=$ LV end-systolic volume; $\mathrm{P}=$ platelet; $\mathrm{WBC}=$ white blood count.

Table 2. Bivariate correlation and linear regression analysis of $\mathrm{H}-\mathrm{FABP}$ and other variables

\begin{tabular}{lccccc}
\hline \multirow{2}{*}{ Variables } & \multicolumn{2}{c}{ Bivariate correlation } & & \multicolumn{2}{c}{ Linear regression analysis } \\
\cline { 2 - 3 } & $\mathrm{r}$ & $\mathrm{p}$ & & $\beta$ & $\mathrm{p}$ \\
\hline Age & -0.28 & 0.07 & -0.36 & 0.006 \\
BUN & 0.38 & 0.013 & & 0.05 & 0.72 \\
Creatinine & 0.32 & 0.034 & & 0.3 & 0.024 \\
Sodium & -0.27 & 0.07 & & 0.05 & 0.5 \\
Hemoglobin & -0.28 & 0.06 & -0.02 & 0.87 \\
EF & -0.26 & 0.08 & -0.01 & 0.94 \\
MPO & 0.61 & 0.0001 & 0.41 & 0.009 \\
\hline
\end{tabular}

0.009; table 2). Gender was not associated with H-FABP levels $(\beta=-0.17, \mathrm{p}=0.16)$.

A positive correlation was found between TnT and BUN $(r=0.46, p=0.002)$, potassium $(r=0.31, p=0.046)$, LV end-diastolic volume $(\mathrm{r}=0.46, \mathrm{p}=0.007), \mathrm{LV}$ endsystolic volume $(r=0.29, \mathrm{p}=0.09)$ and MPO $(r=0.32$, $\mathrm{p}=0.03$; table 3 ). A negative correlation was found between TnT and sodium $(\mathrm{r}=-0.29, \mathrm{p}=0.06)$, hemoglobin $(\mathrm{r}=-0.34, \mathrm{p}=0.026)$ and $\mathrm{EF}(\mathrm{r}=-0.29, \mathrm{p}=0.06$; table 3$)$. Demographic characteristics did not significantly affect
Table 3. Bivariate correlation and linear regression analysis of TnT and other variables

\begin{tabular}{lrllll}
\hline Variables & \multicolumn{2}{c}{ Bivariate correlation } & & \multicolumn{2}{c}{ Linear regression analysis } \\
\cline { 5 - 6 } & $\mathrm{r}$ & $\mathrm{p}$ & & $\beta$ & $\mathrm{p}$ \\
\hline BUN & 0.46 & 0.002 & & -0.62 & 0.78 \\
Sodium & -0.29 & 0.06 & -0.25 & 0.92 \\
Potassium & 0.31 & 0.046 & -0.84 & 0.71 \\
Hemoglobin & -0.34 & 0.026 & & -0.12 & 0.6 \\
LVEDV & 0.46 & 0.007 & & 0.36 & 0.45 \\
LVESV & 0.29 & 0.09 & & -0.08 & 0.87 \\
EF & -0.29 & 0.06 & & 0.1 & 0.68 \\
MPO & 0.32 & 0.03 & & 0.22 & 0.44 \\
\hline
\end{tabular}

LVEDV = LV end-diastolic volume; LVESV = LV end-systolic volume.

serum TnT levels. Multiple linear regression analyses showed that bivariate predictors were not significantly associated with TnT levels in the linear regression analyses (table 3).

\section{Discussion}

In this study, age, creatinine level and MPO level were independent determinants of H-FABP. However, there was no independent relation between MPO and TnT. Previous studies demonstrated that age and renal function are associated with H-FABP $[17,18]$. H-FABP immunoreactivity has been detected not only in cardiomyocytes but also in the renal epithelial cells [19]. Niizeki et al. [18] showed renal function to be significantly associated with H-FABP levels, which was confirmed by our results. In our study, while MPO was an independent predictor of serum H-FABP, it was not associated with TnT. This is similar to the study by Niizeki et al. [20], who reported that H-FABP (but not TnT) was an independent predictor of cardiac events in patients with chronic HF. A probable explanation for this observation could be the molecular sizes of H-FABP and Tnt; while H-FABP is a small protein abundant in the cytosol [9], TnT is a component of the myofibrillar contractile apparatus, present in small amounts in the cytosol $[9,13]$. Hence, due to its small size, H-FABP is released quickly into the circulation when membrane integrity is compromised. Thus, it could be postulated that MPO primarily affects cytosolic proteins, rather than myofibrillar components.
44 
The association and interaction of H-FABP with molecular mediators has been the subject of previous studies on patients with HF [21]. Setsuta et al. [21] showed that tumor necrosis factor, soluble Fas, atrial natriuretic peptide, brain natriuretic peptide and norepinephrine levels were significantly associated with serum H-FABP levels in patients with chronic HF. In addition, our study shows the association of MPO and serum H-FABP in chronic HF patients.

The pathophysiological role of serum MPO levels in patients with HF has been reported [2-4]. Numerous studies have shown increased levels of MPO in HF [3, 4, 22]. Reichlin et al. [3] reported a significant independent association between increased baseline MPO levels and 1-year mortality, while Tang et al. [22] reported that elevated MPO levels were associated with adverse clinical outcomes in patients with HF. They further reported that increasing MPO levels were associated with an increasing likelihood of restrictive diastolic dysfunction and right ventricular systolic dysfunction [22]. Rudolph et al. [6] reported that circulating MPO mRNA levels were significantly increased in patients with LV dysfunction. They also found that the MPO level was an independent predictor of LV impairment [6]. In addition to the role of MPO mentioned in these studies, MPO may also contribute to myocardial damage in patients with HF.

The mechanism that likely links MPO with myocardial damage is that MPO alters myocardial function [5, $23,24]$. In animal models of ischemia, MPO facilitated myocardial remodeling [23]. It has been shown that MPO-null mice subjected to chronic LV dysfunction underwent less LV remodeling than wild-type mice [5]. MPO has been shown to oxidize endothelial-derived ni- tric oxide, to catalyze the oxidation of lipoproteins and to activate metalloproteinases, thus impairing vascular function $[25,26]$. It has also been reported to adversely affect myocardial perfusion by impairing vascular function, thereby contributing to ventricular dysfunction [27]. Eleuteri et al. [28] showed that nitrosative stress is significantly associated with MPO levels, particularly in severely diseased chronic HF patients. They also found a significant correlation between MPO and pro-brain natriuretic peptide levels. They suggested that increased MPO levels may alter myocardial function by increased nitric oxide consumption and protein nitration in these patients. Taking all these mechanisms into account, it can be postulated that increased MPO levels may responsible for the development of myocardial damage in patients with chronic HF.

This study had several limitations including the number of patients and the lack of assessment of other markers of myocardial damage such as CK-MB and myoglobin. In addition, evaluation of the myocardial damage with current advanced imaging techniques such nuclear magnetic resonance and photon emission tomography was not performed.

\section{Conclusions}

A significant association between MPO levels and $\mathrm{H}$ FABP levels was observed, thereby indicating that increased MPO levels may contribute to ongoing myocardial damage in patients with chronic HF. However, it must be taken into consideration that MPO had different effects on H-FABP and TnT.

\section{References}

1 La Rocca G, Di Stefano A, Eleuteri E, et al: Oxidative stress induces myeloperoxidase expression in endocardial endothelial cells from patients with chronic heart failure. Basic Res Cardiol 2009;104:307-320.

2 Ikitimur B, Karadag B: Role of myeloperoxidase in cardiology. Future Cardiol 2010;6: 693-702.

3 Reichlin T, Socrates T, Egli P, et al: Use of myeloperoxidase for risk stratification in acute heart failure. Clin Chem 2010;56:944-951.

-4 Tang WH, Brennan ML, Philip K, et al: Plasma myeloperoxidase levels in patients with chronic heart failure. Am J Cardiol 2006;98: 796-799.
5 Askari AT, Brennan ML, Zhou X, et al: Myeloperoxidase and plasminogen activator inhibitor 1 play a central role in ventricular remodeling after myocardial infarction. J Exp Med 2003;197:615-624.

6 6 Rudolph V, Rudolph TK, Hennings JC, et al: Activation of polymorphonuclear neutrophils in patients with impaired left ventricular function. Free Radic Biol Med 2007;43:11891196.

7 Salonen I, Huttunen K, Hirvonen MR, et al: Serum myeloperoxidase is independent of the risk factors of atherosclerosis. Coron Artery Dis 2012;23:251-258.
8 Arslan S, Erol MK, Kiziltunc A, et al: The relationship between serum myeloperoxidase levels and major cardiovascular events in patients with acute coronary syndrome. Arch Turk Soc Cardiol 2005;33:452-459.

-9 Niizeki T, Takeishi Y, Arimoto T, et al: Persistently increased serum concentration of heart-type fatty acid-binding protein predicts adverse clinical outcomes in patients with chronic heart failure. Circ J 2008;72:109-114.

10 Setsuta K, Seino Y, Ogawa T, et al: Use of cytosolic and myofibril markers in the detection of ongoing myocardial damage in patients with chronic heart failure. Am J Med 2002; 113:717-722. 
11 Collinson PO, Gaze DC: Biomarkers of cardiovascular damage. Med Princ Pract 2007; 16:247-261.

12 Schaap FG, van der Vusse GJ, Glatz JF: Fatty acid-binding proteins in the heart. Mol Cell Biochem 1998;180:43-51.

13 Adams JE 3rd, Abendschein DR, Jaffe AS: Biochemical markers of myocardial injury. Is MB creatine kinase the choice for the 1990s? Circulation 1993;88:750.

14 Lang RM, Bierig M, Devereux RB, et al: Recommendations for chamber quantification. Eur J Echocardiogr 2006;7:79-108.

-15 Kleine AH, Glatz JF, Van Nieuwenhoven FA, et al: Release of heart fatty acid-binding protein into plasma after acute myocardial in farction in man. Mol Cell Biochem1992;116: 155-162.

16 Gaze DC, Collinson PO: Clinical effect of recalibration of the Roche cardiac troponin T assay. Med Princ Pract 2006;15:29-32.

17 Pelsers MM: Fatty acid-binding protein as marker for renal injury. Scand J Clin Lab Invest Suppl 2008;241:73-77.
18 Niizeki T, Takeishi Y, Takabatake N, et al: Circulating levels of heart-type fatty acidbinding protein in a general Japanese population: effects of age, gender, and physiologic characteristics. Circ J 2007;71:1452-1457.

19 Watanabe K, Wakabayashi H, Veerkamp JH, et al: Immunohistochemical distribution of heart-type fatty acid-binding protein immunoreactivity in normal human tissues and in acute myocardial infarct. J Pathol 1993;170: $59-65$.

20 Niizeki T, Takeishi Y, Arimoto T, et al: Hearttype fatty acid-binding protein is more sensitive than troponin $\mathrm{T}$ to detect the ongoing myocardial damage in chronic heart failure patients. J Card Fail 2007;13:120-127.

21 Setsuta K, Seino Y, Ogawa T, et al: Ongoing myocardial damage in chronic heart failure is related to activated tumor necrosis factor and Fas/Fas ligand system. Circ J 2004;68:747750.

22 Tang WH, Tong W, Troughton RW, et al: Prognostic value and echocardiographic determinants of plasma myeloperoxidase levels in chronic heart failure. J Am Coll Cardiol 2007;49:2364-2370.
23 Vasilyev N, Williams T, Brennan ML, et al: Myeloperoxidase-generated oxidants modulate left ventricular remodeling but not infarct size after myocardial infarction. Circulation 2005;112:2812-2820.

24 Heymans S, Luttun A, Nuyens D, et al: Inhibition of plasminogen activators or matrix metalloproteinases prevents cardiac rupture but impairs therapeutic angiogenesis and causes cardiac failure. Nat Med 1999;5:1135-1142.

25 Eiserich JP, Baldus S, Brennan ML, et al: Myeloperoxidase, a leukocyte-derived vascular NO oxidase. Science 2002;296:2391-2394.

26 Lau D, Baldus S: Myeloperoxidase and its contributory role in inflammatory vascular disease. Pharmacol Ther 2006;111:16-26.

27 Bauersachs J, Schafer, A: Endothelial dysfunction in heart failure: mechanisms and therapeutic approaches. Curr Vasc Pharmacol 2004;2:115-124.

28 Eleuteri E, Di Stefano A, Ricciardolo FL, et al: Increased nitrotyrosine plasma levels in relation to systemic markers of inflammation and myeloperoxidase in chronic heart failure. Int J Cardiol 2009;135:386-390. 